\title{
Usefulness of Silent MR Angiography for Intracranial Aneurysms Treated with a Flow-Diverter Device
}

\author{
(D) H. Oishi, (D)T. Fujii, (D) M. Suzuki, (D) N. Takano, (D). Teranishi, (D) K. Yatomi, (D)T. Kitamura, (D) M. Yamamoto, (D) S. Aoki, and (D) H. Arai
}

\begin{abstract}
BACKGROUND AND PURPOSE: The flow-diverter device has been established as a treatment procedure for large unruptured intracranial aneurysms. The purpose of this study was to compare the usefulness of Silent MR angiography and time-of-flight MRA to assess the parent artery and the embolization state of the aneurysm after a flow-diverter placement.
\end{abstract}

MATERIALS AND METHODS: Seventy-eight large, unruptured internal carotid aneurysms in 78 patients were the subjects of this study. After 6 months of treatment, they underwent follow-up digital subtraction angiography, Silent MRA, and TOF-MRA, performed simultaneously. All images were independently reviewed by 2 neurosurgeons and 1 radiologist and rated on a 4-point scale from 1 (not visible) to 4 (excellent) to evaluate the parent artery. The aneurysmal embolization status was assessed with 2 ratings: complete or incomplete occlusion.

RESULTS: The mean scores of Silent MRA and TOF-MRA regarding the parent artery were $3.18 \pm 0.72$ and $2.31 \pm 0.86$, respectively, showing a significantly better score with Silent MRA $(P<.01)$. In the assessment of the embolization of aneurysms on Silent MRA and TOF-MRA compared with DSA, the percentages of agreement were $91.0 \%$ and $80.8 \%$, respectively.

CONCLUSIONS: Silent MRA is superior for visualizing blood flow images inside flow-diverter devices compared with TOF-MRA. Furthermore, Silent MRA enables the assessment of aneurysmal embolization status. Silent MRA is useful for assessing the status of large and giant unruptured internal carotid aneurysms after flow-diverter placement.

$\mathrm{T}$ he advancement of endovascular treatment devices for intracranial aneurysms has been remarkable. In the treatment of large and giant intracranial aneurysms, a flow-diverter device with a high metal coverage ratio is placed in the parent artery so that it decreases blood flow into aneurysms, promotes thrombosis, and thereby prevents rupture. The usefulness of the flow-diverter device has become apparent by various large-scale studies, and its adoption is consistently increasing. ${ }^{1-6}$ However, due to the characteristics of the device, which divert the blood flow and promote thrombosis, careful radiologic follow-up observation is required, and periodic checkups on the status of the aneurysmal embolization and patency of the parent artery are essential. The standard test of follow-up for endovascular treatment of intracra-

Received February 1, 2019; accepted after revision March 25.

From the Departments of Neuroendovascular Therapy (H.O., T.F., T.K.), Neurosurgery (H.O., K.T., K.Y., M.Y., H.A.), and Radiology (M.S., N.T., S.A.), Juntendo University Faculty of Medicine, Tokyo, Japan.

This work was supported by Medtronic.

Please address correspondence to Takashi Fujii, MD, Department of Neuroendovascular Therapy, Juntendo University Faculty of Medicine, 2-1-1 Hongo, Bunkyo-ku, Tokyo 113-8421, Japan; e-mail: takashigreengreen@yahoo.co.jp

http://dx.doi.org/10.3174/ajnr.A6047 nial aneurysms is digital subtraction angiography. Because DSA itself is invasive and involves the risk of complications and adverse effects caused by contrast agents and radiation exposure, less invasive and simple examination procedures are warranted. ${ }^{7-10}$ In recent years, the usefulness of contrast-enhanced MR angiography has often been reported, ${ }^{11,12}$ though using gadolinium carries the risk of serious complications such as nephrogenic systemic fibrosis. ${ }^{13}$ Therefore, time-of-flight MRA has been gaining attention as a viable imaging procedure without having to use a contrast agent. ${ }^{14,15}$ However, there have been some skeptical views regarding its accuracy. ${ }^{11,12}$

We have reported the usefulness of Silent MRA (GE Healthcare, Milwaukee, Wisconsin) as a radiologic follow-up procedure after coil embolization for intracranial aneurysms. ${ }^{16-18}$ Silent MRA is a procedure using an ultrashort TE and arterial spinlabeling techniques, which efficiently visualizes the status after the treatment of intracranial aneurysms. In Silent MRA, the 3D image is reconstructed by subtracting the control image from the image obtained by the labeling pulse. At the beginning of its development, although it was a procedure that literally silences the noise of the MR imaging, Silent MRA was attracting attention because its imaging capability after endovascular treatment is superior to 


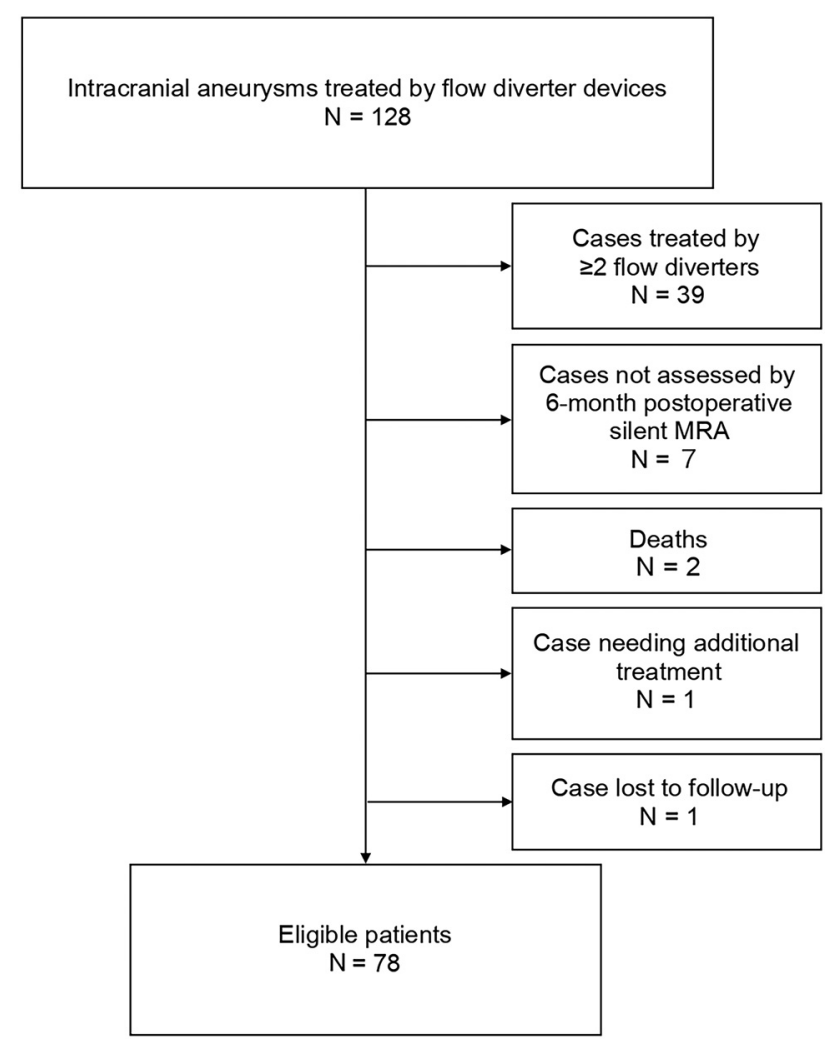

FIG 1. A flowchart of eligible patients assessed by Silent MR angiography after Pipeline Flex placement for intracranial aneurysms.

that of other modalities. To date, there have been several reports on the comparison of the assessment procedures between TOFMRA and contrast-enhanced MRA after flow-diverter placement therapy. ${ }^{12,19,20}$ To our knowledge, this is the first study of the comparison of Silent MRA and TOF-MRA after flow-diverter placement in intracranial aneurysms, in as much as we searched medical search engines using the key words "Silent MRA," "TOFMRA" and "flow diverter." We report here the posttreatment assessment of flow-diverter therapy by Silent MRA in a study with a population of 78 patients along with the bibliographic consideration of the relevant literature.

\section{MATERIALS AND METHODS \\ Patient and Aneurysm Characteristics}

We retrospectively studied aneurysms treated with 1 flow-diverter device (Pipeline Flex Embolization Device; Covidien, Irvine, California) between June 2015 and February 2018. The patients treated with $\geq 2$ flow-diverter devices were excluded to avoid the effects of excess metal artifacts. Among the 128 patients treated with flow-diverter devices during the study, there were 78 patients, excluding 39 patients who were treated with $\geq 2$ flow diverter devices, 7 patients who did not undergo Silent MRA at the 6-month follow-up, 2 patients who were not examined due to postoperative death, 1 patient who needed additional treatment, and 1 patient who dropped out of the study for personal reasons (Fig 1).

Because this study was noninvasive and retrospective, patients' informed consent was not required. We obtained approval for this study from the ethics review board.
Table 1: Characteristics of the patients assessed by DSA, Silent MRA, and TOF-MRA after placement of flow-diverter devices

\begin{tabular}{lc}
\multicolumn{1}{c}{ Parameters } & Data \\
\hline Age (mean) (range) (yr) & $61.4 \pm 13.3(19-82)$ \\
Sex (M/F) & $6: 72$ \\
Side (R/L) & $36: 42$ \\
Location (cavernous segment/paraclinoid segment) & $52: 26$ \\
Aneurysmal size (mean) (range) (mm) & $14.8 \pm 5.5(10.0-32.5)$ \\
Aneurysmal neck diameter (mean) (range) (mm) & $6.5 \pm 2.2(2.8-15.3)$ \\
Symptomatic cases (No.) (\%) & $23(29.5 \%)$ \\
Additional coiling (No.) (\%) & $39(50 \%)$ \\
Pipeline diameter (mean) (range) (mm) & $4.2 \pm 0.6(3-5)$ \\
Pipeline length (mean) (range) (mm) & $21.8 \pm 6.3(16-35)$ \\
In-stent percutaneous transluminal angioplasty (No.) (\%) & $52(66.7 \%)$ \\
In-stent stenosis (No.) (\%) & \\
$\quad$ None (0\%) & $28(38.9 \%)$ \\
Mild (0-25\%) & $41(52.6 \%)$ \\
$\quad$ Moderate ( $\geq 25 \%)$ & $9(11.5 \%)$ \\
Duration of follow-up (mean) (range) (mo) & $6.1 \pm 0.6(4-8)$ \\
\hline
\end{tabular}

Note:- R indicates right; L, left.

The patients' characteristics are summarized in Table 1 . We evaluated all patients on the basis of Silent MRA, TOF-MRA, and DSA, which were undergone postoperatively at approximately 6 months. DSA was performed for endovascular treatment and for postoperative assessment using the Artis Q BA Twin biplane system (Siemens, Erlangen, Germany).

\section{Endovascular Procedure}

Preoperative loading of antiplatelet agents began at least 10 days before with a dose of $100 \mathrm{mg}$ of aspirin and 50-75 mg of clopidogrel, with the dose determined according to body weight. For patients who might possibly have late-onset rupture of intracranial aneurysms, additional coil embolization was performed to promote thrombosis. ${ }^{21-23}$ Additional in-stent percutaneous transluminal angioplasty was performed if the patients were found to have poor adhesion of the Pipeline Flex from the results of intraoperative DSA and conebeam CT. All the patients continuously received postoperative administration of dual-antiplatelet therapy until the 6-month Silent MRA follow-up was performed. All treatments for all patients were performed by one of the authors (H.O.), who has $>20$ years of experience conducting endovascular procedures.

\section{MRA Scan Parameters}

TOF-MRA and Silent MRA were performed with 3T MRA (Discovery MR750w; GE Healthcare). Imaging parameters for Silent MRA were the following: TR/TE, $642.8 / 0.016 \mathrm{~ms}$; flip angle, $5^{\circ}$; FOV, $180 \times 180 \mathrm{~mm}$; matrix, $150 \times 150$; section thickness, 1.0 $\mathrm{mm}$; NEX, 1; bandwidth, $\pm 31.2 \mathrm{kHz}$; acquisition time, $12 \mathrm{~min}-$ utes 13 seconds. Imaging parameters for TOF-MRA were the following: TR/TE, 20/2.9 ms; flip angle, $18^{\circ}$; FOV, $200 \times 200 \mathrm{~mm}$; matrix, $416 \times 224$; section thickness, $1.0 \mathrm{~mm}$; NEX, 1; bandwidth, $\pm 41.7 \mathrm{kHz}$; acquisition time, 4 minutes 45 seconds. Although the detailed algorithm for Silent MRA has not been disclosed, the arterial spin-labeling technique was used as a preparation pulse, and data were obtained by a $3 \mathrm{D}$ radial scan. ${ }^{24}$

\section{Image Analysis}

Images in DSA, Silent MRA, and TOF-MRA before treatment and after 6 months were reviewed independently by 2 neurosurgeons (H.O. and T.F.) and 1 radiologist (M.S.). Assessment parameters were location of the aneurysm, size, and neck diameter. The per- 
centage of in-stent stenosis was measured at the narrowest site in DSA. It was classified into 3 levels: none $(0 \%)$, mild (0\%-25\%), and moderate $(25 \%-50 \%)$. In-stent blood flow was rated on a 4-point scale: 1 , not visible (signal alteration not detected or cannot be assessed); 2 , poor (blood flow slightly visible, but not adequate for diagnosis); 3, acceptable (blood flow roughly visible, diagnosable images); and 4, excellent (images almost equal to DSA). Scores of in-stent signals were calculated as the mean of those assessed by the 3 observers. Mean scores of the high- and the low-score groups were $>2$ and $\leq 2$, respectively. Scores for Silent MRA and TOF-MRA were assessed. The percentage of agreement of scores by 3 observers was also assessed. The status of embolization of aneurysms observed by DSA, Silent MRA, and TOF-MRA was assessed with a 2-point rating scale: 1 , incomplete occlusion (intra-aneurysmal signal alteration recognized); and 2, complete occlusion (no intra-aneurysmal signal alterations recognized). In case of discrepancy among the 3 observers, the images were reviewed by 3 other observers (K.T., K.Y., and M.Y.) to confirm the embolization status of all the aneurysms, determining whether complete or incomplete occlusion was achieved by rechecking the DSA, Silent MRA, and TOF-MRA. The rate of agreement of the embolization status between DSA and Silent MRA and TOFMRA was also assessed.

\section{Thrombosis after Pipeline Flex Placement}

When an intra-aneurysmal signal alteration after the treatment of an aneurysm was not observed by Silent MRA, but was observed

Table 2: Comparison of correlations between Silent MRA and TOF-MRA from the viewpoint of all parameters for Silent MRA $(3.18 \pm 0.72)$

\begin{tabular}{lccc}
\hline & $\begin{array}{c}\text { High Score } \\
(>2, \boldsymbol{n}=66)\end{array}$ & $\begin{array}{c}\text { Low Score } \\
(\leq 2, \boldsymbol{n}=12)\end{array}$ & $\begin{array}{c}\boldsymbol{P} \\
\text { Value }\end{array}$ \\
\hline Aneurysmal size (mean) (mm) & $14.8 \pm 5.4$ & $15.0 \pm 6.6$ & .91 \\
Aneurysmal neck diameter (mean) (mm) & $6.5 \pm 2.2$ & $6.4 \pm 2.3$ & .79 \\
Pipeline diameter (mean) (mm) & $4.3 \pm 0.6$ & $4.1 \pm 0.6$ & .27 \\
Pipeline length (mean) (mm) & $21.7 \pm 6.3$ & $22.0 \pm 6.8$ & .90 \\
In-stent stenosis (No.) (\%) & $42 / 66(63.6 \%)$ & $8 / 12(66.7 \%)$ & .84 \\
Location (paraclinoid/cavernous) & $44: 22$ & $8: 4$ & 1.00 \\
Additional coiling (No.) (\%) & $33 / 66(50.0 \%)$ & $7 / 12(58.3 \%)$ & .60 \\
\hline
\end{tabular}

Table 3: Comparison of correlations between Silent MRA and TOF-MRA from the viewpoint of all parameters for TOF-MRA $(2.31 \pm 0.86)$

\begin{tabular}{lccc}
\hline & $\begin{array}{c}\text { High Score } \\
(>2, \boldsymbol{n}=\mathbf{4 4})\end{array}$ & $\begin{array}{c}\text { Low Score } \\
(\leq 2, \boldsymbol{n}=34)\end{array}$ & $\begin{array}{c}\boldsymbol{P} \\
\text { Value }\end{array}$ \\
\hline Aneurysmal size (mean) (mm) & $13.5 \pm 4.3$ & $16.6 \pm 6.5$ & $<.05$ \\
Aneurysmal neck diameter (mean) (mm) & $6.0 \pm 1.6$ & $7.2 \pm 2.7$ & $<.05$ \\
Pipeline diameter (mean) (mm) & $4.2 \pm 0.6$ & $4.3 \pm 0.5$ & .61 \\
Pipeline length (mean) (mm) & $20.8 \pm 5.8$ & $23.0 \pm 6.9$ & .13 \\
In-stent stenosis (No.) (\%) & $28 / 44(63.6 \%)$ & $22 / 34(65.9 \%)$ & .92 \\
Location (paraclinoid/cavernous) & $35: 9$ & $17: 17$ & $<.01$ \\
Additional coiling (No.) (\%) & $26 / 44(59.1 \%)$ & $14 / 34(41.2 \%)$ & .12 \\
\hline
\end{tabular}

Table 4: Comparison of correlation between Silent MRA and TOF-MRA from the viewpoint of intra-aneurysmal thrombosis after flow-diverter device placement

\begin{tabular}{lccc}
\hline & $\begin{array}{c}\text { Intra-Aneurysmal } \\
\text { Thrombosis }(+)(\boldsymbol{n}=13)\end{array}$ & $\begin{array}{c}\text { Intra-Aneurysmal } \\
\text { Thrombosis }(-)(\boldsymbol{n}=65)\end{array}$ & $\begin{array}{c}\boldsymbol{P} \\
\text { Value }\end{array}$ \\
\hline Location (paraclinoid segment/cavernous segment) & $2: 11$ & $63: 2$ & $<.01$ \\
Aneurysmal size (mean) (range) (mm) & $21.7 \pm 5.3(12.6-32.5)$ & $13.4 \pm 4.4(8.1-28.7)$ & $<.01$ \\
Aneurysmal neck diameter (mean) (range) (mm) & $7.8 \pm 3.1(2.8-15.3)$ & $6.3 \pm 1.9(3.3-13.9)$ & $<.05$ \\
Additional coiling (No.) (\%) & $2(15.4 \%)$ & $37(56.9 \%)$ & $<.01$ \\
Pipeline diameter (mean) (range) (mm) & $4.21 \pm 0.5(3-5)$ & $4.23 \pm 0.6(3-5)$ & .91 \\
Pipeline length (mean) (range) (mm) & $27.5 \pm 7.2(18-35)$ & $20.6 \pm 5.4(16-35)$ & $<.01$ \\
Silent MRA score (mean) & $3.5 \pm 0.5$ & $3.1 \pm 0.7$ & .10 \\
TOF-MRA score (mean) & $2.0 \pm 0.8$ & $2.3 \pm 0.8$ & .20 \\
\hline
\end{tabular}

Note:- + indicates present; -, absent.

810 Oishi May 2019 www.ajnr.org by TOF-MRA, the status was interpreted as intra-aneurysmal thrombosis after the Pipeline Flex placement. Thrombosis was reported as a region showing a high-intensity signal on both TOFMRA and a T1-weighted image ${ }^{25}$; and it was confirmed that in all cases, the signal in the aneurysm was a high-intensity signal on a T1-weighted image. It has been reported that assessment of the status of the parent artery and intra-aneurysmal status revealed on TOF-MRA are more difficult in the event of an intra-aneurysmal thrombosis. ${ }^{12,17}$ Aneurysms treated with Pipeline Flex placement were divided into 2 groups, those with and those without thromboses. The assessment items were the following: location, aneurysmal size and neck diameter, presence or absence of additional coiling, diameter and length of Pipeline Flex, and the difference in the scores between Silent MRA and TOF-MRA.

\section{Statistical Analysis}

Each value was expressed by mean \pm SD and range. The difference between 2 groups was assessed by a $t$ test or the $\chi^{2}$ test. $P<.05$ was considered to indicate statistical significance. The rate of agreement among the 3 observers was expressed by the Fleiss $\kappa$ coefficient.

\section{RESULTS}

The patients' characteristics are summarized in Table 1 .

The mean score of Silent MRA, $3.18 \pm 0.72$, was significantly higher than that of TOF-MRA, $2.31 \pm 0.86(P<.01)$. The Fleiss $\kappa$ coefficient was 0.408. In Tables 2 and 3, correlation between Silent MRA and TOF-MRA was shown from the viewpoint of parameters in the groups with high $(>2)$ and low $(\leq 2)$ mean scores. The scores of Silent MRA were not influenced by any of these parameters, whereas the scores of TOF-MRA were statistically significantly low when the aneurysmal size and neck diameter were large and the aneurysm was located in the cavernous segment.

Comparisons of the correlation between Silent MRA and TOFMRA from the viewpoint of intra-aneurysmal thrombosis after Pipeline Flex placement are summarized in Table 4. Thrombosis occurred frequently after Pipeline Flex placement in a statistically significant manner under the following conditions: Aneurysms were located in the cavernous segment, the aneurysm was large, there was an absence of additional coiling, and the Pipeline was long.

Embolization of aneurysms was assessed in comparisons of DSA, Silent MRA, and TOF-MRA by dividing the patients with complete or incomplete occlusion of aneurysms (Table 5). The rate of agreement between Silent MRA and DSA and TOF-MRA and DSA was $91.0 \%$ and $80.8 \%$, respectively.

\section{DISCUSSION}

In the present study, we used the flow-diverter device, Pipeline Flex, with a high metal coverage ratio. Consequently, Silent MRA was better in terms of visualizing in-stent blood flow and the embolic state of aneurysms compared with TOF-MRA in a statistically significant manner. Particularly, Silent MRA showed superior visualization regardless of the maximum size of the aneurysmal diameter, diameter and length of the Pipeline Flex itself, the location of the aneurysms, the degree of 
in-stent stenosis, and the presence or absence of additional coiling. On the other hand, TOF-MRA showed significantly poor visualization of large aneurysms and those located in the cavernous segment (Fig 2).

With TOF-MRA, it has become known that within an artery, such as in the cavernous segment with considerable bends and meandering, there are often signal losses due to turbulent and/or slow flow. ${ }^{26-29}$ The TOF-MRA score tended to be lower when the neck diameter was larger and the Pipeline Flex was longer, though it was not statistically significant. One of the causes of these results was the effect of the metal artifacts of the Pipeline Flex. On the other hand, although artifacts due to additional coiling were speculated to be the cause of poor imaging, such an effect was not observed. The cause was thought to be that during the Pipeline placement, because the purpose of coil embolization was not complete occlusion but to promote thrombosis, coiling induced only rough packing, and consequently the metal surface area was small.

In the present study, in TOF-MRA images after Pipeline Flex placement, there were cases in which occlusion of the parent artery was difficult and which were mistakenly diagnosed as incomplete intra-aneurysmal occlusion due to the intra-aneurysmal thrombosis signals (Fig 3). The aneurysm will be completely oc-

Table 5: Comparison of embolization assessment among DSA, Silent MRA, and TOF-MRA after flow-diverter device placement

\begin{tabular}{llcc}
\hline & & \multicolumn{2}{c}{ DSA } \\
\cline { 3 - 4 } & & $\mathrm{CO}(\boldsymbol{n}=\mathbf{5 5})$ & $\mathrm{IO}(\boldsymbol{n}=\mathbf{2 3})$ \\
\hline Silent MRA & $\mathrm{CO}(n=58)$ & 53 & 5 \\
& $\mathrm{IO}(n=20)$ & 2 & 18 \\
TOF-MRA & $\mathrm{CO}(n=52)$ & 47 & 7 \\
& $\mathrm{IO}(n=26)$ & 8 & 16 \\
\hline
\end{tabular}

Note:-CO indicates complete occlusion; IO, incomplete occlusion. cluded by promoting intra-aneurysmal thrombosis after flow-diverter placement. It is reported that TOF-MRA shows a highintensity signal from an acute-to-subacute phase of thrombus formation. ${ }^{25}$ The thrombosis signal change of TOF-MRA was particularly frequent in the cavernous segment, the segment in which additional coiling was not required, presumably because the thrombosis occurred slowly and it was easy to pick up the signal change in TOF-MRA. The Silent MRAs and the 3D images were reconstituted by subtraction of data from the control image of those obtained by labeling pulse, signals of thrombosis after the flow-diverter placement can be removed. This means that Silent MRA does not pick up a thrombosis signal, but, like DSA, it shows only a blood flow signal into the aneurysm as a signal change. Similarly, in contrast-enhanced MRA, signals of thrombosis can be eliminated by the subtraction between control and contrastenhanced images. However, it is possible that false-positive alterations of intra-aneurysmal signals such as venous contamination and enhancement of the aneurysmal wall were observed with contrast-enhanced MRA. ${ }^{30}$ In any event, postoperative assessment of a flow-diverter device that promotes aneurysmal thrombosis may be difficult by TOF-MRA. In the present study, signal alterations due to thrombosis were examined in chronologic order (Fig 3). Immediately after the treatment, there was no area with highintensity signals on the T1-weighted image. Six months later, signals due to thrombosis reached a peak, and 1 year later the signals slightly decreased. Immediately after the treatment, Silent MRA visualized intra-aneurysmal signal alteration due to the remaining blood, while at 6 months and again at 1 year later, no signal alterations were observed. Furthermore, it was found that the percentage of agreement in the assessment of intra-aneurysmal embolization on Silent MRA was higher than that on TOF-MRA.

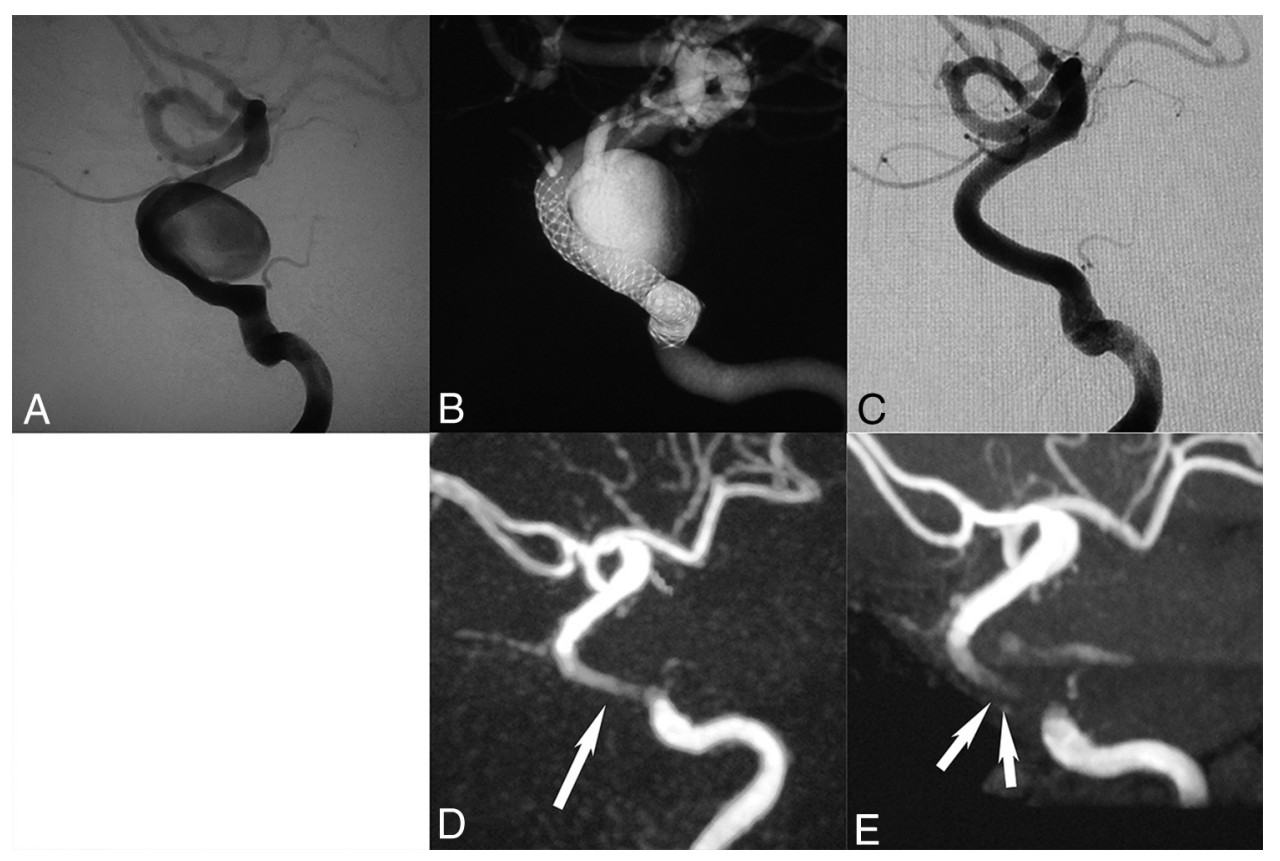

FIG 2. A, An 82-year-old woman. Flow-diverter placement in the left internal carotid artery cavernous segment aneurysm $(20.1 \times 6.3 \mathrm{~mm})$ was performed with the Pipeline Flex $(4.5 \times 25 \mathrm{~mm})$. B. Digital subtraction angiography shows the location of the Pipeline Flex by conebeam CT. C, The 6-month follow-up DSA shows complete occlusion of the aneurysm. D, This Silent MRA shows an excellent signal flow in the Pipeline Flex (arrow) but no intra-aneurysmal signal. E, This time-of-flight MRA almost lost the signal in the Pipeline Flex (double arrows) and has a faint signal in the aneurysm. The scores of the Silent MRA by 3 observers were 4,3 , and 4 , and those of the TOF-MRA were 2, 2, and 2. 


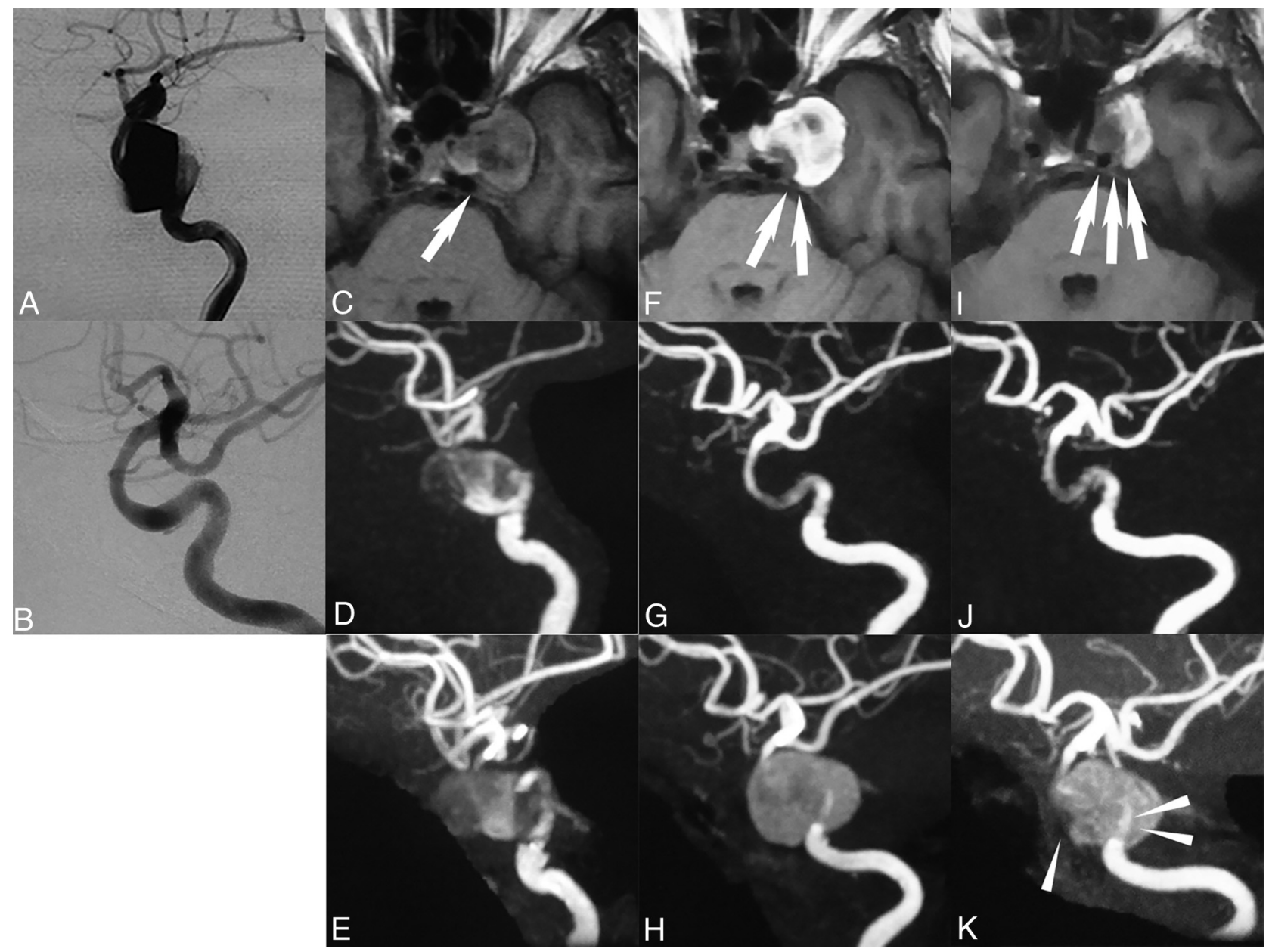

FIG 3. A 75 -year-old woman. A, The aneurysm $(26.2 \times 6.1 \mathrm{~mm})$ was located in the left internal carotid artery paraclinoid segment. B, A 6-month follow-up DSA shows almost complete occlusion of the aneurysm. C, The MRA T1-weighted image immediately after the operation shows an intra-aneurysmal isointensity signal (arrow). $D$ and $E$, Both Silent MRA and TOF-MRA show an intra-aneurysmal signal that had a negative influence on the parent artery assessment. F, A 6-month follow-up T1-weighted image shows an intra-aneurysmal high-intensity signal, which means thrombosis (double arrows). G, A 6-month follow-up, Silent MRA shows excellent signal flow in the Pipeline Flex. H, A 6-month follow-up TOF-MRA shows that the image could not be assessed by the intra-aneurysmal thrombosed signal. $I$, The 1-year follow-up T1-weighted MR image shows a lower intra-aneurysmal high-intensity signal decrease than at the 6-month follow-up (triple arrows). J, The 1-year follow-up findings on the Silent MRA signal flow were the same as at the 6-month follow-up. $K$, The 1-year follow-up on TOF-MRA shows a better signal flow than at the 6-month follow-up TOF-MRA (arrowhead) by improvement of the thrombosed aneurysm (double arrowheads), but the signal flow on the Silent MRA is better than that on the TOF-MRA. The scores of the 6-month follow-up Silent MRA by 3 independent observers were 4, 4, and 4. The scores of the TOF-MRA were 1,1 , and 1 .

Especially, intra-aneurysmal thrombosis was likely to contribute to the high rate of false-positive signals on TOF-MRA.

In the present study, there were 2 cases in which TOF-MRA showed significantly better images than Silent MRA (Fig 4). In 1 patient, a 65-year-old woman, the images were not clear, probably due to artifacts caused by the woman's denture. Because the arterial spin-labeling technique was used for Silent MRA, a labeling pulse was performed through the patient's cervical region. Therefore, although Silent MRA is useful even if there are intracranial metal artifacts, cervical artifacts such as a denture could possibly influence the image. The other case was that of a 73-year-old woman. This patient was claustrophobic and could not stay still during the MR imaging examination. As a result, visualization was poor due to motion artifacts. Silent MRA imaging takes 12 minutes 13 seconds, which is significantly longer than the 4 minutes 45 seconds needed for a TOF-MRA. Therefore, for claustro- phobic patients, children, or elderly and postoperatively restless patients, TOF-MRA is preferable.

There are some limitations to the present study. First, we have not assessed contrast-enhanced MRA. There have been some studies that report that contrast-enhanced MRA is excellent for the postoperative assessment of stent placement and flow-diverter placement. Although Silent MRA was found to be superior to TOF-MRA in the present study, comparison with contrast-enhanced MRA is warranted. Second, the present assessment was limited to internal carotid aneurysms. Recently, flow-diverter devices for the posterior circulation have been developed, and their usefulness has been demonstrated. ${ }^{31}$ In the future, the assessment of the posterior circulation should be performed. Third, the present study was retrospective. A prospective study with a high level of evidence-based medicine would be desirable. 


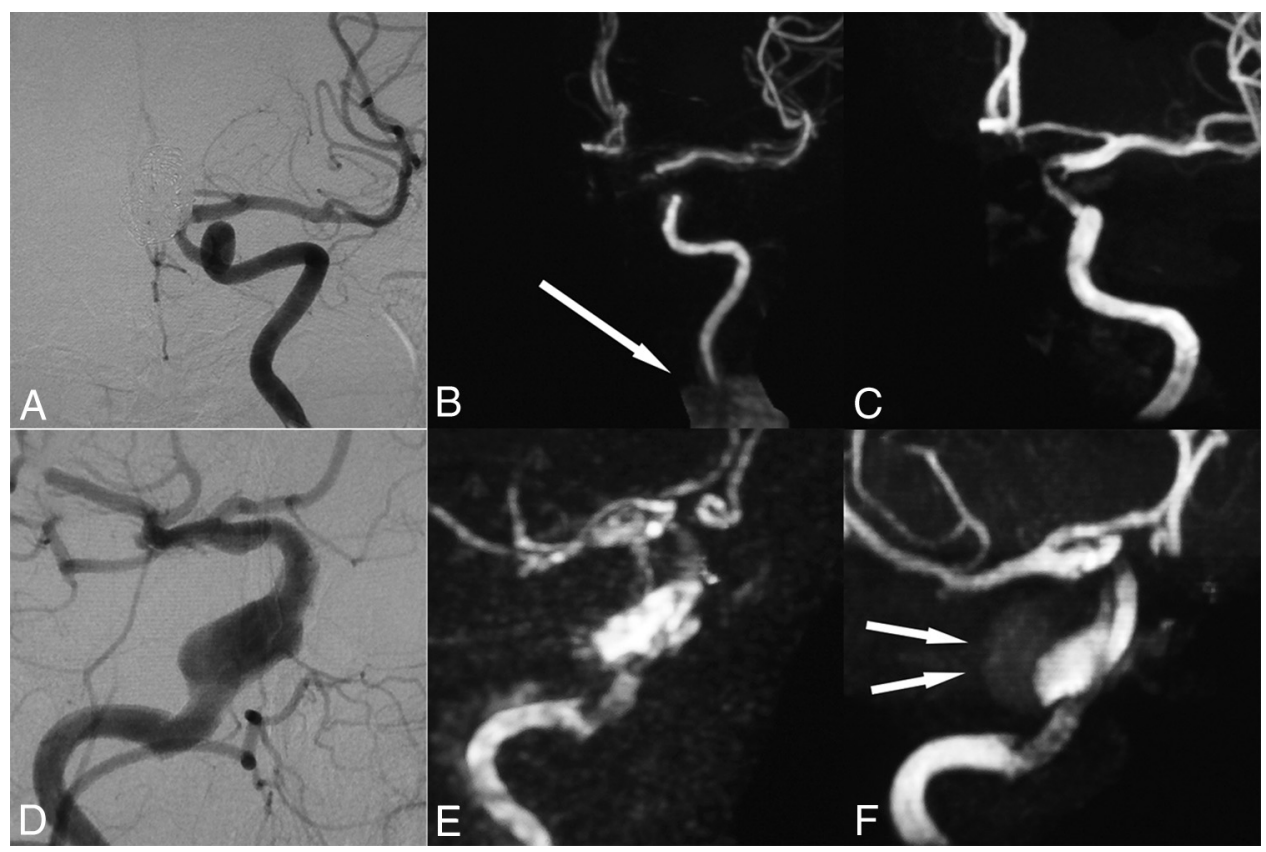

FIG 4. A-C, A 62-year-old woman. $A$, The 6-month follow-up DSA shows complete occlusion and good patency in the Pipeline Flex. $B$ and $C$, The 6-month follow-up Silent MRA shows a worse signal flow than the TOF-MRA due to artifacts caused by the left denture (arrow). The Silent MRA scores by 3 independent observers were 2, 1, and 2, while the TOF-MRA scores were 3, 2, and 3. D-F, A 73-year-old woman. D, The 6-month follow-up DSA shows reduction of intra-aneurysmal flow. $E$ and $F$, The 6-month follow-up Silent MRA shows a poor signal caused by motion artifacts because the patient was claustrophobic and moved during the procedure, and TOF-MRA also shows a poor signal flow caused by an intra-aneurysmal thrombosis after the Pipeline Flex placement (double arrows). The scores of Silent MRA by 3 independent observers were 3 , 3 , and 3. The scores of TOF-MRA were 2, 3, and 4.

\section{CONCLUSIONS}

In the postoperative assessment of Pipeline Flex placement for large and giant unruptured internal carotid aneurysms after 6 months, Silent MRA showed superior visualization of both instent signals and the status of intra-aneurysmal embolization compared with TOF-MRA. Given these results, Silent MRA techniques to assess intra-aneurysmal blood flow after Pipeline Flex placement will become more effective.

Disclosures: Hidenori Oishi-RELATED: Grant: Medtronic, Comments: a donation in the form of a research fund to the endowed chair; Consulting Fee or Honorarium: Medtronic, Comments: More than one million Japanese yen. Shigeki Aoki-UNRELATED: Grants/Grants Pending: Mediphysics, Toshiba, Bayer AG, Daiichi Sankyo, Eisai, Fujiyakuhin, Fujifilm RI, Guerbet, Comments: grant for diagnostic radiology*; Payment for Lectures Including Service on Speakers Bureaus: Mediphysics, Toshiba, Bayer AG, Daiichi Sankyo, Eisai, Fujiyakuhin, Fujifilm RI, Canon, Guerbet, Comments: grant for diagnostic radiology; Payment for Manuscript Preparation: honorarium for lectures/chair from GE Healthcare, Toshiba/Canon, Hitachi, Siemens, Bayer AG, Daiichi Sankyo, Eisai, Fujiyakuhin, Fujifilm RI, Mediphysics, Novartis, Takeda Pharmaceutical Company, Biogen, Chugai Pharmaceutical Co was paid to individual; Payment for Development of Educational Presentations: Gakken Medical Shujunsha, Miwa Shoten Publishers. *Money paid to the institution.

\section{REFERENCES}

1. Nelson PK, Lylyk P, Szikora I, et al. The Pipeline Embolization Device for the intracranial treatment of aneurysms trial. AJNR Am J Neuroradiol 2011;32:34-40 CrossRef Medline

2. Becske T, Kallmes DF, Saatci I, et al. Pipeline for uncoilable or failed aneurysms: results from a multicenter clinical trial. Radiology 2013; 267:858-68 CrossRef Medline

3. Kallmes DF, Hanel R, Lopes D, et al. International retrospective study of the Pipeline Embolization Device: a multicenter aneurysm treatment study. AJNR Am J Neuroradiol 2015;36:108-15 CrossRef Medline

4. Liu JM, Zhou Y, Li Y, et al; PARAT investigators. Parent artery re- construction for large or giant cerebral aneurysms using the Tubridge Flow Diverter: a multicenter, randomized, controlled clinical trial (PARAT). AJNR Am J Neuroradiol 2018;39:807-16 CrossRef Medline

5. Keskin F, Erdi F, Kaya B, et al. Endovascular treatment of complex intracranial aneurysms by Pipeline flow-diverter embolization device: a single-center experience. Neurol Res 2015;37:359-65 CrossRef Medline

6. Lubicz B, Van der Elst O, Collignon L, et al. Silk flow-diverter stent for the treatment of intracranial aneurysms: a series of 58 patients with emphasis on long-term results. AJNR Am J Neuroradiol 2015; 36:542-46 CrossRef Medline

7. Ferns SP, Sprengers ME, van Rooij WJ, et al. Coiling of intracranial aneurysms: a systematic review on initial occlusion and reopening and retreatment rates. Stroke 2009;40:e523-29 CrossRef Medline

8. Kanaan H, Jankowitz B, Aleu A, et al. In-stent thrombosis and stenosis after neck-remodeling device-assisted coil embolization of intracranial aneurysms. Neurosurgery 2010;67:1523-32; discussion 1532-33 CrossRef Medline

9. Mocco J, Fargen KM, Albuquerque FC, et al. Delayed thrombosis or stenosis following Enterprise-assisted stent-coiling: is it safe? Midterm results of the interstate collaboration of Enterprise stent coiling. Neurosurgery 2011;69:908-13; discussion 913-14 CrossRef Medline

10. Briganti F, Leone G, Marseglia M, et al. Endovascular treatment of cerebral aneurysms using flow-diverter devices: a systematic review. Neuroradiol J 2015;28:365-75 CrossRef

11. Agid R, Schaaf M, Farb R. CE-MRA for follow-up of aneurysms post stent-assisted coiling. Interv Neuroradiol 2012;18:275-83 CrossRef Medline

12. Boddu SR, Tong FC, Dehkharghani S, et al. Contrast-enhanced timeresolved MRA for follow-up of intracranial aneurysms treated with the Pipeline Embolization Device. AJNR Am J Neuroradiol 2014;35: 2112-18 CrossRef Medline

13. Penfield JG, Reilly RF. Nephrogenic systemic fibrosis risk: is there a 
difference between gadolinium-based contrast agents? Semin Dial 2008;21:129-34 CrossRef Medline

14. Cho WS, Kim SS, Lee SJ, et al. The effectiveness of 3T time-of-flight magnetic resonance angiography for follow-up evaluations after the stent-assisted coil embolization of cerebral aneurysms. Acta Radiol 2014;55:604-13 CrossRef Medline

15. Cho YD, Kim KM, Lee WJ, et al. Time-of-flight magnetic resonance angiography for follow-up of coil embolization with Enterprise stent for intracranial aneurysm: usefulness of source images. Korean J Radiol 2014;15:161-68 CrossRef Medline

16. Irie R, Suzuki M, Yamamoto M, et al. Assessing bold flow in an intracranial stent: a feasibility study of MR angiography using a Silent scan after stent-assisted coil embolization for anterior circulation aneurysms. AJNR Am J Neuroradiol 2015;36:967-70 CrossRef Medline

17. Takano N, Suzuki M, Irie R, et al. Usefulness of non-contrast-enhanced MR angiography using a Silent scan for follow-up after Yconfiguration stent-assisted coil embolization for basilar tip aneurysms. AJNR Am J Neuroradiol 2017;38:577-81 CrossRef Medline

18. Takano N, Suzuki M, Irie R, et al. Non-contrast-enhanced Silent scan MR angiography of intracranial anterior circulation aneurysms treated with a low-profile visualized intraluminal support device. AJNR Am J Neuroradiol 2017;38:1610-16 CrossRef Medline

19. Attali J, Benaissa A, Soize S, et al. Follow-up of intracranial aneurysms treated by flow diverter: comparison of three-dimensional time-of-flight MR angiography (3D-TOF-MRA) and contrast-enhanced MR angiography (CE-MRA) sequences with digital subtraction angiography as the gold standard. J Neurointerv Surg 2016;8: 81-86 CrossRef Medline

20. Patzig M, Forbrig R, Ertl L, et al. Intracranial aneurysms treated by flow-diverting stents: long-term follow-up with contrast-enhanced magnetic resonance angiography. Cardiovasc Intervent Radiol 2017; 40:1713-22 CrossRef Medline

21. Benaissa A, Tomas $\mathrm{C}$, Clarençon $\mathrm{F}$, et al. Retrospective analysis of delayed intraparenchymal hemorrhage after flow-diverter treatment: presentation of a retrospective multicenter trial. AJNR Am J Neuroradiol 2016;37:475-80 CrossRef Medline
22. Cruz JP, Chow M, O'Kelly C, et al. Delayed ipsilateral parenchymal hemorrhage following flow diversion for the treatment of anterior circulation aneurysms. AJNR Am J Neuroradiol 2012;33:60-68 CrossRef Medline

23. Kulcsár Z, Houdart E, Bonafe A, et al. Intra-aneurysmal thrombosis as a possible cause of delayed aneurysm rupture after flow-diversion treatment. AJNR Am J Neuroradiol 2011;32:20-25 CrossRef Medline

24. Alibek S, Vogel M, Sun W, et al. Acoustic noise reduction in MRI using Silent Scan: an initial experience. Diagn Interv Radiol 2014;20: 360-63 CrossRef Medline

25. Renard D, Le Bars E, Arquizan C, et al. Time-of-flight MR angiography in cerebral venous sinus thrombosis. Acta Neurol Belg 2017;117: 837-40 CrossRef Medline

26. Wall A, Kugel H, Bachman R, et al. 3.0 T vs. 1.5 T MR angiography: in vitro comparison of intravascular stent artifacts. J Magn Reson Imaging 2005;22:772-79 CrossRef Medline

27. Wang Y, Truong TN, Yen C, et al. Quantitative evaluation of susceptibility and shielding effects of nitinol, platinum, cobalt-alloy, and stainless steel stents. Magn Reson Med 2003;49:972-76 CrossRef Medline

28. Majoie CB, Sprengers ME, van Rooij WJ, et al. MR angiography at 3T versus digital subtraction angiography in the follow-up of intracranial aneurysms treated with detachable coils. AJNR Am J Neuroradiol 2005;26:1349-56 Medline

29. Wallace RC, Karis JP, Partovi S, et al. Noninvasive imaging of treated cerebral aneurysms, part 1: MR angiographic follow-up of coiled aneurysms. AJNR Am J Neuroradiol 2007;28:1001-08 CrossRef Medline

30. Choi JW, Roh HG, Moon WJ, et al; Time-resolved 3D contrastenhanced MRA on 3.0T: a non-invasive follow-up technique after stent-assisted coil embolization of the intracranial aneurysm. Korean J Radiol 2011;12:662-70 CrossRef Medline

31. Leucking H, Engelhorn T, Lang S, et al. FRED flow diverter: a study on safety and efficacy in a consecutive group of 50 patients. AJNR Am J Neuroradiol 2017;38:596-02 CrossRef Medline 